Article

\title{
Field Propagation Experiments of Male African Savanna Elephant Rumbles: A Focus on the Transmission of Formant Frequencies
}

\author{
Anton Baotic ${ }^{1, *(\mathbb{D}}$, Maxime Garcia ${ }^{1,2} \mathbb{D}$, Markus Boeckle ${ }^{3,4}$ and Angela Stoeger ${ }^{1, *(\mathbb{D}}$ \\ 1 Mammal Communication Lab, Department of Cognitive Biology, University of Vienna, Vienna 1090, Austria; \\ maxime.garcia@ymail.com \\ 2 ENES Lab, Neuro-PSI, CNRS UMR 9197, University of Lyon/Saint Etienne, 42023 Saint Etienne, France \\ 3 Department of Psychology, University of Cambridge, Cambridge CB2 3EB, UK; markus.boeckle@gmail.com \\ 4 Department of Psychotherapy, Bertha von Suttner University, St. Poelten 3100, Austria \\ * Correspondence: anton.baotic@univie.ac.at (A.B.); angela.stoeger-horwath@univie.ac.at (A.S.)
}

Received: 27 August 2018; Accepted: 25 September 2018; Published: 30 September 2018

check for updates

Simple Summary: African savanna elephants are highly social and exhibit a complex vocal communication system. They use a low-frequency contact call (termed 'rumble') to maintain social contact over long distances. As sound travels through the environment, however, its intensity level decreases. We used specialized computer software to manipulate acoustic components in male rumbles and simulated different body sizes (large and small). The rumbles were broadcasted and re-recorded at different distances at the Addo Elephant National Park, South Africa. This propagation experiment enabled us to investigate which acoustic components and information content can be transmitted efficiently up to $1.5 \mathrm{~km}$. The results confirm that male rumbles potentially encode information about body size, yet transmission success decreased with distance. Our findings inform on how the environment can influence propagation of savanna elephant rumbles and what kind of information might be transmitted successfully over distance.

\begin{abstract}
African savanna elephants live in dynamic fission-fusion societies and exhibit a sophisticated vocal communication system. Their most frequent call-type is the 'rumble', with a fundamental frequency (which refers to the lowest vocal fold vibration rate when producing a vocalization) near or in the infrasonic range. Rumbles are used in a wide variety of behavioral contexts, for short- and long-distance communication, and convey contextual and physical information. For example, maturity (age and size) is encoded in male rumbles by formant frequencies (the resonance frequencies of the vocal tract), having the most informative power. As sound propagates, however, its spectral and temporal structures degrade progressively. Our study used manipulated and resynthesized male social rumbles to simulate large and small individuals (based on different formant values) to quantify whether this phenotypic information efficiently transmits over long distances. To examine transmission efficiency and the potential influences of ecological factors, we broadcasted and re-recorded rumbles at distances of up to $1.5 \mathrm{~km}$ in two different habitats at the Addo Elephant National Park, South Africa. Our results show that rumbles were affected by spectral-temporal degradation over distance. Interestingly and unlike previous findings, the transmission of formants was better than that of the fundamental frequency. Our findings demonstrate the importance of formant frequencies for the efficiency of rumble propagation and the transmission of information content in a savanna elephant's natural habitat.
\end{abstract}

Keywords: African savanna elephant; rumble; vocalization; formant; propagation 


\section{Introduction}

Many group-living mammal species have developed complex social and spatiotemporal association patterns [1]. Depending on the costs involved to maintain social cohesion, groups may temporarily split and vary in size as they move through the environment, helping balance the costs and benefits of grouping. Spatial coordination in such dynamic fission-fusion societies requires communication and information transfer/exchange between multiple signalers and receivers in their active space [2,3]. Vocal signals may transmit information about a caller's identity and physical attributes (age, body size, and sex) and are particularly important for facilitating social recognition and mating success [4]. In this context, a key objective will often be to maximize the propagation distance in the animal's natural habitat [5], which in turn depends on the receiver's ability of assessing a vocal signal's degradation level to determine a nearby caller's distance (termed 'ranging') and to mediate interindividual spacing [6].

In general, as sound waves propagate through the environment, the spectral and temporal structure degrades progressively with distance, yielding a $6 \mathrm{~dB}$ attenuation of the signal amplitude (source intensity that corresponds to sound pressure) per distance doubling (termed 'spherical spreading') under frictionless open field conditions, i.e., far from any obstructions. This potentially constrains the signal's active space and thus affects decoding acoustic information by receivers [7-9]. Further factors causing 'excess attenuation' are ambient noise, fluctuations or changes of atmospheric conditions, vegetation strata, topography, and reverberation (frequency-dependent repeated reflections of a signal). Attenuation of higher frequencies and reverberation are more pronounced in dense habitats due to tree trunks, branches, and foliage, whereas open field habitats possess fewer reflecting barriers. In open habitats, however, irregular atmospheric conditions, such as high wind speeds or temperature, may affect sound propagation [7-12]. Studies in baboons [13] and birds [14,15] demonstrated the beneficial effect of sound reflection on sound transmission. Accordingly, reflected sound waves can contribute energy to the source sound wave when both waves overlap and hence affect sound propagation. Ground effects are caused by constructive or destructive interference effects, between sound traveling from a source to a receiver and sound being reflected from the ground that occur at a receiver's location resulting, respectively, either in enhancement or attenuation of a received sound pressure level SPL (usually given in decibels, dB) [16]. But signal amplitude/SPL alone has been suggested not to be a reliable acoustic cue to assess the distance of a sound source as (1) a signaler could vary its amplitude when facing away from or towards a listener and (2) acoustic signals can be affected by the attenuation factors mentioned above [17-19]. These attenuation factors differ between habitats and influence the acoustic characteristics of signals due to overall temporal degradation, frequency-dependent attenuation, and degradation processes $[7,8,12]$. Additional temporal and spectral structures of a signal are more likely to contribute to a more complete set of acoustic cues for distance assessment and information decoding than only amplitude/SPL, as it has been demonstrated in frogs [20], birds [18], and mammals (e.g., elephant seals [21] and bison [22]). Overall, lower-frequency sound experiences less attenuation than higher-frequency sound $[8,12,23,24]$; various mammal species use low-frequency vocalizations to maintain social relationships with conspecifics over distance [25-27].

Low-frequency communication is well developed in the African savanna elephant (Loxodonta africana) [28], a socially and spatially flexible species [29,30]. Though they produce a range of different vocalizations, the low-frequency 'rumble' is the most frequently produced call type. The rumble is a harmonically-rich vocalization with frequency components near or in the infrasonic range, used for both short- and long-distance communication [28,31-34]. In savanna elephants, rumbles are known to transfer information about identity, sex, age, size, arousal, and reproductive state [32,34-38], and enable communication over long distances to coordinate movements and to maintain contact between spatially separated individuals [34,39].

In general, sound production mechanisms in mammal species can be explained by the 'source-filter' theory, which states that a vocal signal is generated by vibrations of the vocal folds in the larynx (source) and modified acoustically by the vocal tract (filter) between the larynx and the 
mouth [40]. The dimensions of the vocal folds (length and thickness) and their average vibration rate define the fundamental frequency $\left(f_{o}\right)[40,41]$. Comparative perceptual studies in other mammals, such as in deer [42], koalas [43], and domestic dogs [44], showed that vocal tract resonance frequencies (formants) are a reliable cue to body size and are therefore biologically relevant [4]. Vocal tract (VT) length and body size are anatomically correlated in savanna elephants [37,38]; VT length generally determines formant dispersion ( $\mathrm{F} \Delta$, average spacing between successive formants). This in turn provides acoustic information about body weight and mass. The longer the vocal tract, the lower the formants and the narrower the overall $\mathrm{F} \Delta$ [45].

The influence of an animal's body size on its sound production and vocal performance is an important biological constraint [46]. In a wide range of terrestrial mammals with pronounced sexual size dimorphism, it has been suggested that individuals, typically males, are able to produce vocalizations with lowered formants and formant dispersions. This may be achieved, for example, by extending the VT (e.g., red deer Cervus elaphus), by utilizing additional resonators, or by developing nasal proboscises (e.g., elephant seal Mirounga sp.). These adaptations help broadcast an exaggerated impression of body size in vocalizations involved in reproductive contexts (for a comprehensive review see the literature [47]). The savanna elephant's nasal vocal tract is exceptionally elongated compared to its oral vocal tract and hence occupies a special position amongst mammal vocal production. Savanna elephants follow the basic mechanism of mammalian sound production [48] and can make use of their nasal vocal path to emit rumbles. This enables them to lower their formant frequencies compared to orally emitted rumbles, making nasal rumbles particularly suitable to communicate over long distances [49]. Nonetheless, the adaptive significance of formant modulations in savanna elephants remains unknown: do the very low formant frequencies of rumbles reflect sexual (or other social) selection pressures to sound larger, or do they reflect natural selection pressures to maximize call propagation distances? Note that both selection pressures could be operating and are not necessarily mutually exclusive.

In the present study, we applied a resynthesis technique on male savanna elephant social rumbles to create playback stimuli with different formant variations for field propagation experiments. We manipulated the most consistent formant locations (i.e., the first and second formants, $F 1$ and $F 2$, respectively) while leaving the $f_{o}$ unchanged, and generated stimuli with apparent vocal tract length differences simulating different male body sizes (i.e., two different maturity groups). This approach was designed to determine whether lower formants propagate further than higher formants in comparable conditions while other parameters remain unchanged, and to evaluate the active communication range (information transmission) during daytime conditions. By broadcasting and re-recording rumbles at increasing distance, we quantified the extent to which size-related information degrades with increasing distance in a savanna elephant's natural environment. Our experimental and analytical approach also enabled us to assess the impact of two different habitats and environmental conditions on transmission properties in this long-distance call.

\section{Materials and Methods}

\subsection{Sound Recordings of Playback Stimuli}

The rumbles used in the propagation experiments originated from four adult male savanna elephants from four South African private elephant reserves (Table 1) recorded in social (nonreproductive) contexts (e.g., when individuals maintained vocal contact with other group members during free-roaming and browsing activities in areas of 3 to $45 \mathrm{~km}^{2}$ ). Acoustic recordings were conducted throughout the day between $7 \mathrm{AM}$ and $5 \mathrm{PM}$ by following the animals on foot accompanied by the keepers, without any interaction with the animals. Recording distances of the selected vocalizations were less than $10 \mathrm{~m}$ from the calling individual.

We used an omni-directional Neumann KM183 condenser microphone (fitted with a windshield), modified for recording frequencies below $20 \mathrm{~Hz}$ (flat-recording down to $5 \mathrm{~Hz}$ ). The microphone was 
connected to a Sound Devices 722 (frequency response: $10 \mathrm{~Hz}-40 \mathrm{kHz},+0.1,-0.5 \mathrm{~dB}$ (gain controls centered); Sound Devices LLC, Reedsburg, WI, USA), recording rumbles with a $48 \mathrm{kHz}$ sampling rate and an amplitude resolution of 16 bits.

Table 1. Study sites and age for each study subject.

\begin{tabular}{llcc}
\hline Location, Year of Data Collection & Individual & Age (Years) & Approx. Shoulder Height (m) \\
\hline Pilanesberg, 2014 & Mike & $\sim 29$ & $3.20 \mathrm{~m}$ \\
Bela Bela, 2014 & Chishuru & $\sim 18$ & $2.40 \mathrm{~m}$ \\
Hazyview, 2014 & Medwa & $\sim 19$ & $2.60 \mathrm{~m}$ \\
Addo Elephant Back Safaries, 2016 & Thaba & $\sim 31$ & $3.25 \mathrm{~m}^{1}$ \\
\hline
\end{tabular}

$\sim$ indicates that the exact birth date is unknown. ${ }^{1}$ Shoulder height measured in 2014.

\subsection{Study Site and Conditions}

Transmission experiments were conducted at the Addo Elephant National Park (AENP; 3330' S, $25^{\circ} 45^{\prime} \mathrm{E}$ ), Eastern Cape Province of South Africa, covering an area of approximately $270 \mathrm{~km}^{2}$ (Roxanne Erusan, AENP Scientific Services, personal communication). The AENP is located in the endemic-rich, xeric succulent thicket vegetation (e.g., succulents, deciduous shrubs, lianas, and grass) of the Eastern Cape [50]. AENP hosts a variety of habitats from areas with a high density of thorny thicket vegetation (the most prominent plant is the succulent 'Spekboom', Portulacaria afra) up to $3 \mathrm{~m}$ high (rarely higher) to extensive areas of open grasslands [51]. AENP consists of a series of undulating hills with an altitude range of 60 to $350 \mathrm{~m}$ above sea level [52].

Propagation trials were carried out at two locations: the 'Rooidam' section, representing a densely vegetated habitat with slight height differences ranging from 1 to $13 \mathrm{~m}$, and at the 'Gorah' section, an open grassland habitat with greater height differences (0-59 m). A total of six recording days (three per habitat) were conducted on 26, 30, and 31 March 2017, and on 1, 2, and 4 April 2017, respectively. Sound propagation in the African savannah is best after sunset and 1-2 $\mathrm{h}$ before sunrise when ground level temperature cools down [53]. Experiments started at 05:30 a.m. at the earliest (due to security reasons), and finished at the latest at about 09:00 a.m. under dry and low wind conditions.

\subsection{Experimental Design}

\subsubsection{Preparation of Playback Stimuli}

The focus of this study was on long-range nasal rumbles. The predicted formant locations for nasal rumbles are $F 1=35.0 \mathrm{~Hz}$ and $F 2=105.0 \mathrm{~Hz}$ using an estimated vocal tract (VT) length of $2.5 \mathrm{~m}$ [32]. In general, in savanna elephant vocalizations only the first two formants are consistently present [54-56]. After visual spectrographic inspection of our sound recordings in Praat [57], we preselected one nasal rumble per individual with low levels of background noise, clear $f_{0}$ and upper harmonics including F1 and F2. Rumbles with formants equal or below the predicted values mentioned above were classified as nasally emitted.

For each stimulus a stop Hann band (0-5 Hz) and pass Hann band (6-200 Hz) filter was applied in Praat. This enabled proceeding solely with the relevant frequency ranges and removed as much background noise as possible.

We used the 'To Formant (keep all)' Praat function to inspect each rumble visually and automatically track formants. This yielded the optimal analysis settings (e.g., formant number: 2 , maximum formant: $110 \mathrm{~Hz}$, window length: 0.3 , pre-emphasis: $5 \mathrm{~Hz}$; note that these setting differed according to the rumble used).

Formants were modified using a custom-written script applying the source-filter resynthesis technique in Praat. Each rumble's formant locations were down- and upshifted by $25 \%$. We additionally used a $0 \%$ shift condition, where formants remained in their original position to control for the resynthesis procedure (i.e., original and '0\% shifted' rumbles are identical). Other acoustic parameters 
(e.g., $f_{o}$, duration) remained unchanged for all three variants. All sound stimuli were normalized to a peak intensity of 0.99 , yielding a test set of 12 WAV sound files, i.e., three different shift conditions per individual (see Table S1 for the measured formant values).

\subsubsection{Field Recordings}

To examine the transmission success of rumbles with increasing distance, we played back and re-recorded 504 male rumbles in total (252 per habitat) at 50 m, 100 m, 200 m, 400 m, 800 m, 1000 m, and $1500 \mathrm{~m}$. We used a custom-made subwoofer INFRA10 (dimension: $198 \times 166 \times 171 \mathrm{~mm}$, weight: $\sim 300 \mathrm{~kg}$ ) linked to a rechargeable multipower MP45-12 lead-acid battery and a JL Audio HD1200/1 audio amplifier, connected to a 722 Sound Device HDD recorder to broadcast the playback stimuli. The INFRA10 is constructed for low frequencies, giving a flat response from 10 to $200 \mathrm{~Hz}$ at peak sound pressure levels measured at $1 \mathrm{~m}$ from the source of $110 \mathrm{~dB}$ at $10 \mathrm{~Hz}$ (referenced to $20 \mu \mathrm{Pa}$ ). Stimuli were played back in sequences (with one sequence consisting of all three shift variants) at $105 \mathrm{~dB} \pm 1 \mathrm{~dB}$ at $1 \mathrm{~m}$, measured with a NTi NG AL1 sound pressure level meter equipped with a calibrated NTi MiniSPL microphone (settings: max SPL with SPL/RTA mode and FLAT response (unweighted)). In addition, we compared the playback recordings with the original stimuli in order ensure that signals were broadcasted correctly. Re-recordings were conducted using the identical recording equipment and settings used for recording the stimuli. The recording level remained unchanged and the same for all recording distances during the experiments (set at $60.5 \mathrm{~dB}$ at the 722 Sound Device recorder).

Two operators, using one Toyota Hilux pick-up each, conducted the field experiments. The subwoofer was mounted and transported on the loading zone of one pick-up, $1 \mathrm{~m}$ above the ground (see schematic representation in Figure 1). For each recording distance the subwoofer remained at a fixed position, while the second vehicle (the 'recording vehicle'), from which the playback stimuli were recorded, was moved to the recording distances. During each trial, the playback and recording vehicles were in contact using a Stabo Freecomm 650 PMR radio set and mobile phones. To evaluate each recording distance's position, we used the vehicles' mileage counter and a Nikon Aculon ALL11 laser rangefinder. We additionally used the iOS application GPS Tour 2.0 [58] to track latitude, longitude, and altitude in order to verify the exact position and sea level for each distance (Figure 2). Landmarks were used to permanently mark each relevant distance for the entire experiment. Since GPS receivers use smoothed models of altitude to calculate elevation, we first converted these ellipsoidal heights into topographic heights (using a geoid height calculator [59]) before calculating absolute height differences between recording and subwoofer locations for each transmission distance (Table S2). The microphone was mounted and stabilized on a tripod outside the vehicle. To ensure direct orientation of the microphone towards the subwoofer's broadcast direction, we used Bushnell powerview mid $10 \times 42$ binoculars for adjustments. Due to limited vision between both vehicles in the densely vegetated habitat ( $\sim 3 \mathrm{~m}$ height of succulents), we used additional landmarks at each recording distance to point towards the subwoofer's direction. To do this, the person operating the subwoofer positioned him- or herself centrally on top of the speaker (to be at the same level as the bush thicket), facing the subwoofer's membrane and broadcasting direction. After visually confirming the subwoofer's operator using a binocular, the person operating the recording equipment set the landmarks indicating the direction of the microphone towards the subwoofer for all follow-up trials.

For each distance, one playback sequence (consisting of the three formant shift variants $25 \%$ Down, $0 \%$ Unchanged, and $25 \% \mathrm{Up})$ for each individual $(\mathrm{N}=4)$ was broadcasted, yielding a total of 84 playbacks across all seven recording distances per habitat and day. Depending on the occurrence or intensity of ambient noise (e.g., passing aircrafts), the respective playback sequence was repeated. To document atmospheric state per sequence, we used an anemometer PCE-THA 10 to measure temperature in ${ }^{\circ} \mathrm{C}$, wind speed $(\mathrm{m} / \mathrm{s})$, and relative humidity $(\%)$. 


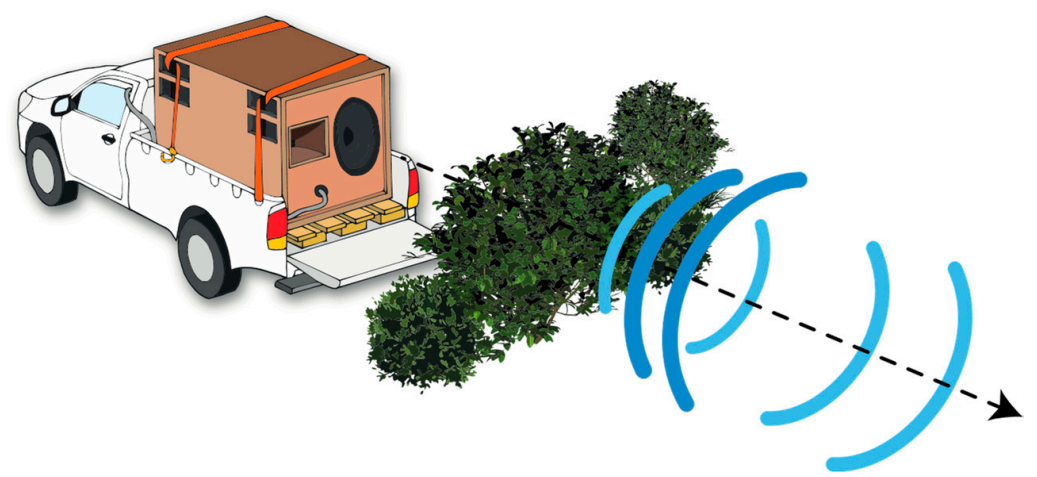

Figure 1. Schematic representation of the positioned infrasonic loudspeaker system at a densely vegetated location. The battery-supplied INFRA10 is mounted on the loading zone of a pick-up and operated inside the vehicle (broadcasting direction of playback stimulus indicated by dashed arrow).
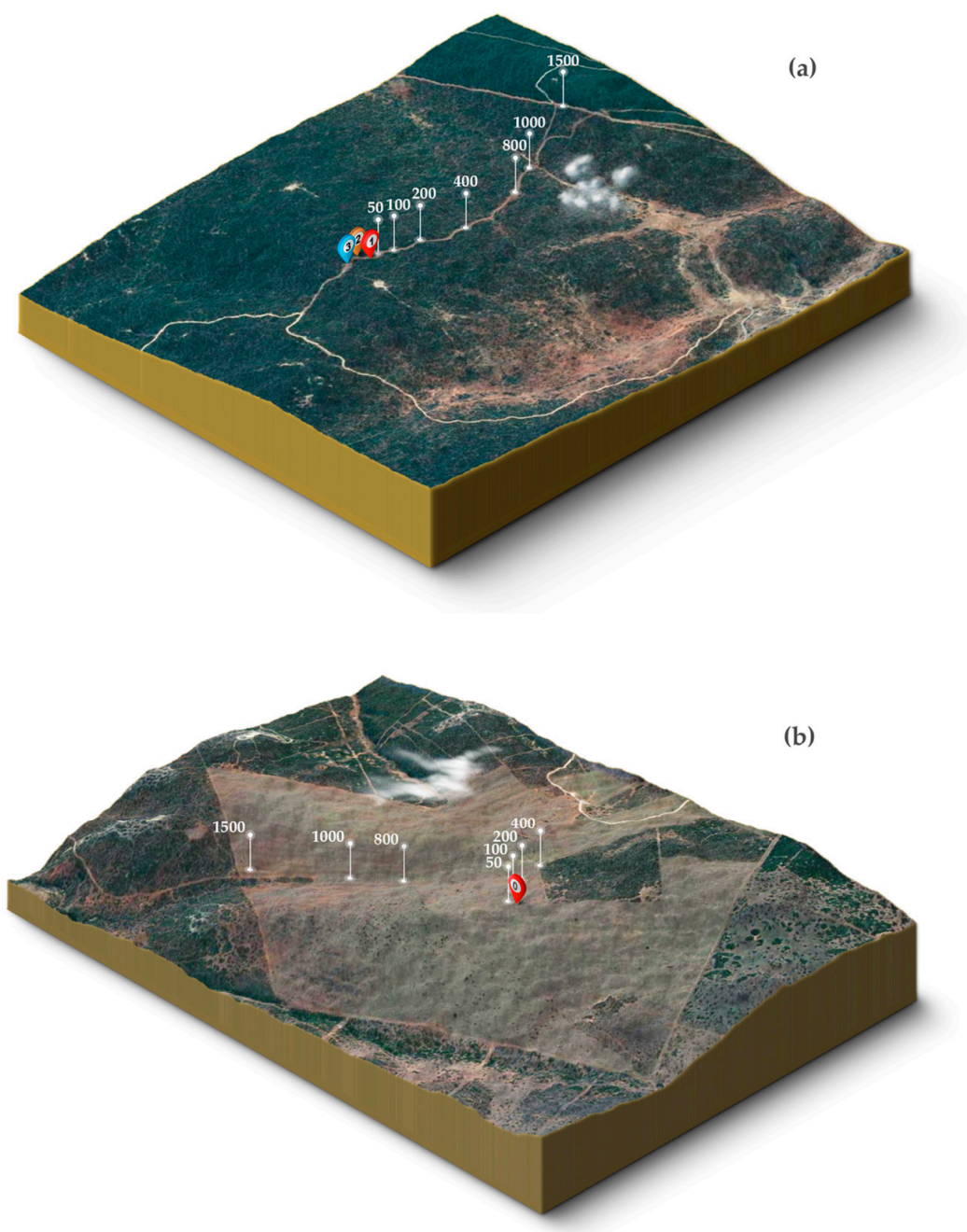

Figure 2. Topographical maps of both study sites, the densely vegetated (a) and the open (b) habitat. Vertical lines indicate the positions for each recording distance, ranging from 50 to $1500 \mathrm{~m}$. The colored and numbered pins represent the fixed position of the subwoofer. In (a), pin \#3 (in blue) corresponds to the position of the subwoofer for $1500 \mathrm{~m}$, pin \#2 (in orange) to the position of the subwoofer for 1000 $\mathrm{m}$, and pin \#1 for all other recording distances. Pin \#0 (red) (b) represents the subwoofer's position used to broadcast playback stimuli for all recording distances. Figures were generated using 3D Map Generator Terrain v1.4.2 (The Orange Box, Berlin, Germany) and Adobe Photoshop CC 2014 (Adobe Systems Incorporated, San Jose, CA, USA). 


\subsection{Acoustic Analyses}

\subsubsection{Fundamental Frequency $\left(f_{o}\right)$ Analysis}

Data were segmented by defining the on- and off-set of each rumble using a customized annotation and labeling tool in S_Tools-STx 4.4.6 [60]. We used a custom-written STx script based on an autocorrelation method to automatically extract source-related $f_{o}$ parameters $f_{o} \min , f_{o} \max , f_{o}$ start, $f_{o}$ end, $f_{o}$ center, and $f_{0}$ mean (in Hertz). This is based on the total number of measuring points (Ntotal), determined by segment length and $f_{o}$ min $\left(f_{o}\right.$ min determines the length of the analysis window that has to correspond to three $f_{0}$ min periods; i.e., the lower $f_{0}$ min, the longer the analysis window). We used a $75 \%$ overlap between successive kessel analysis windows with a bandwidth of $1 \mathrm{~Hz}$. Only the number of frames with nonzero $f_{o}$ values $\left(\mathrm{N} f_{o}\right)$ were considered for further analyses.

\subsubsection{Formant Frequency Location (F1, F2) Analysis and Vocal Tract Length}

Prior to analysis all sound files were downsampled at $500 \mathrm{~Hz}$, resulting in a frequency range of 0 to $250 \mathrm{~Hz}$. Following the computation of LPC (Linear Predictive Coding)-smoothed spectrums in the range of 0 to $250 \mathrm{~Hz}$ using S_Tools-STx 4.4.6 (it was not possible to track formant frequencies continuously over the entire signal in Praat in our long-distance re-recordings), we measured the center frequency (in $\mathrm{Hz}$ ) of the LPC spectral peaks, indicating formant positions. Differing experimental conditions in both habitats, such as higher background noise or wind speed, caused structural variation within the re-recorded sound signals. We therefore allowed a tolerance measurement of $\pm 0.5 \mathrm{~s}$ for the re-recordings based on the original measuring point of the corresponding playback stimuli. That is, if the LPC peak of $F 1$ in the original stimulus was measured at $2.5 \mathrm{~s}, F 1$ in the re-recorded stimulus could be measured between $2 \mathrm{~s}$ and $3 \mathrm{~s}$. A comparison of LPC peak measurements of an original and re-recorded stimulus of all formant shift variants is illustrated in Figure 3.

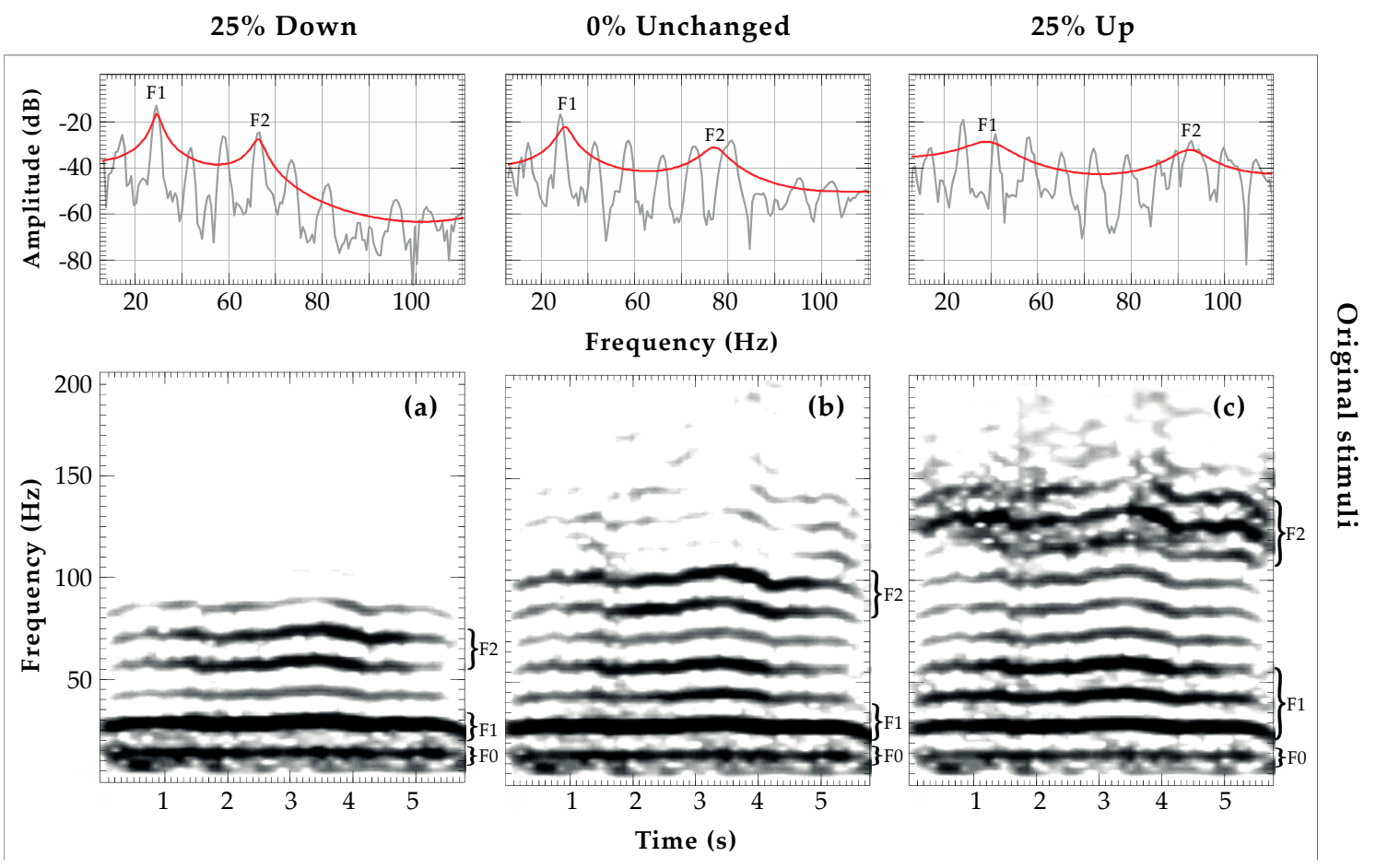

Figure 3. Cont. 




Figure 3. Narrow-band spectrograms and LPC spectra, indicating $f_{0}, F 1$, and $F 2$ location for each shift variant (25\% Down, $0 \%$ Unchanged, and $25 \%$ Up) of the original test data set (a-c) and the corresponding playback recordings from $50 \mathrm{~m}$ distance (d-f) (S_Tools-STx settings; analysis windows: Kaiser kessel, bandwidth: 2, overlap: 75\%).

In the present study, the second formant was less consistent than the first one, making it difficult to calculate F $\Delta$ and, therefore, a predicted VT length. Since VT length affects the overall formant frequency pattern, and the lowest formant potentially provides some information on VT length [45], we used $F 1$ to calculate 'estimated VT lengths' based on the equation $\mathrm{F}_{1}=\frac{\mathrm{c}}{4 \mathrm{~L}}$, where $c$ is the speed of sound ( $343.5 \mathrm{~m} / \mathrm{s}$ [61]), and $L$ is the length of the supralaryngeal vocal tract (assuming that the VT is a resonant tube open at one and closed at the other) [40].

\subsubsection{Amplitude Attenuation of Acoustic Features (SNR)}

To assess the amplitude attenuation of $F 1, F 2$, and $f_{o}$ over distance in both habitats, we calculated the respective 'Signal-to-noise Ratio' (SNR) of these parameters with a custom-written script in S_Tools-STx. To examine environmental background noise levels alone, we extracted a $0.5 \mathrm{~s}$ segment directly before the onset and after the offset of each playback sequence. Root Mean Square (RMS) values for the environmental background noise were then computed at three frequencies (those corresponding to $F 1, F 2$, and $f_{o}$ in the playback segment) from an averaging of both noise segments. In parallel, for each playback segment, three RMS values were also measured, exactly at $F 1, F 2$, and $f_{o}$. For each of these parameters, SNR was then determined by subtracting the RMS of the averaged noise segment (again only at the frequency of $F 1$ and not over the entire frequency range) from the RMS of the playback segment. This procedure was applied to determine SNR for $F 1, F 2$, and $f_{o}$ independently.

\subsection{Statistical Analyses}

To provide a way of determining 'transmission success' of playbacks through the environment, we calculated absolute numbers and percentages of successfully transmitted rumbles for each recording distance. Rumbles with a $\mathrm{N}_{o}$ detection rate below $60 \%$ were treated as insufficiently detected and hence discarded from further analysis. To assess the stability of the acoustic features, we compared F1, $F 2, f_{0}$ mean, and duration of rumbles with successful transmissions at 100 to $1500 \mathrm{~m}$ recording distance 
to rumbles obtained from the lowest distance, $50 \mathrm{~m}$, by using nonparametric Mann-Whitney U tests (suited for non-normal distributed data).

Formants in nasal rumbles of savanna elephants encode information on maturity (i.e., age and body size) [37,38]. We therefore used VT length estimations (in $\mathrm{m}$ ) to split our data set into two size groups ('maturity group 1'> $3 \mathrm{~m}$ and 'maturity group 2 ' $\leq 3 \mathrm{~m}$ ). To examine differences between those groups per recording distance and per habitat, we performed Mann-Whitney $U$ tests.

To assess attenuation of $F 1, F 2$, and $f_{0}$ with increasing distance from 50 to $1500 \mathrm{~m}$, for each habitat, the SNR of each acoustic feature was regressed with recording distance using linear regression. The relationship between SNR and distance was then quantified by computing Cohen's effect size index, $\mathrm{f}$ [62], for regression models using equation $\mathrm{f}=\sqrt{\frac{\mathrm{R}^{2}}{1-\mathrm{R}^{2}}}$. All statistical tests were conducted using IBM SPSS statistics version 23 [63]. Significance levels were set at 0.05 and two-tailed statistics are reported.

\section{Results}

\subsection{Transmission Success}

As expected, the propagation experiments conducted at the Addo Elephant National Park showed that the transmission success in two different habitats, densely vegetated and open, decreased with distance. The dense habitat resulted in a transmission success of $93.3 \%$ for $F 1,59.1 \%$ for $F 2$, and $59.1 \%$ for $f_{0}$ mean, whereas in the open habitat $f_{0}$ mean reached $57.5 \%, F 263.1 \%$, and $F 185.7 \%$. The transmission of $F 1$ was most efficient compared to $F 2$ and $f_{0}$ mean in both habitats (Figure 4).
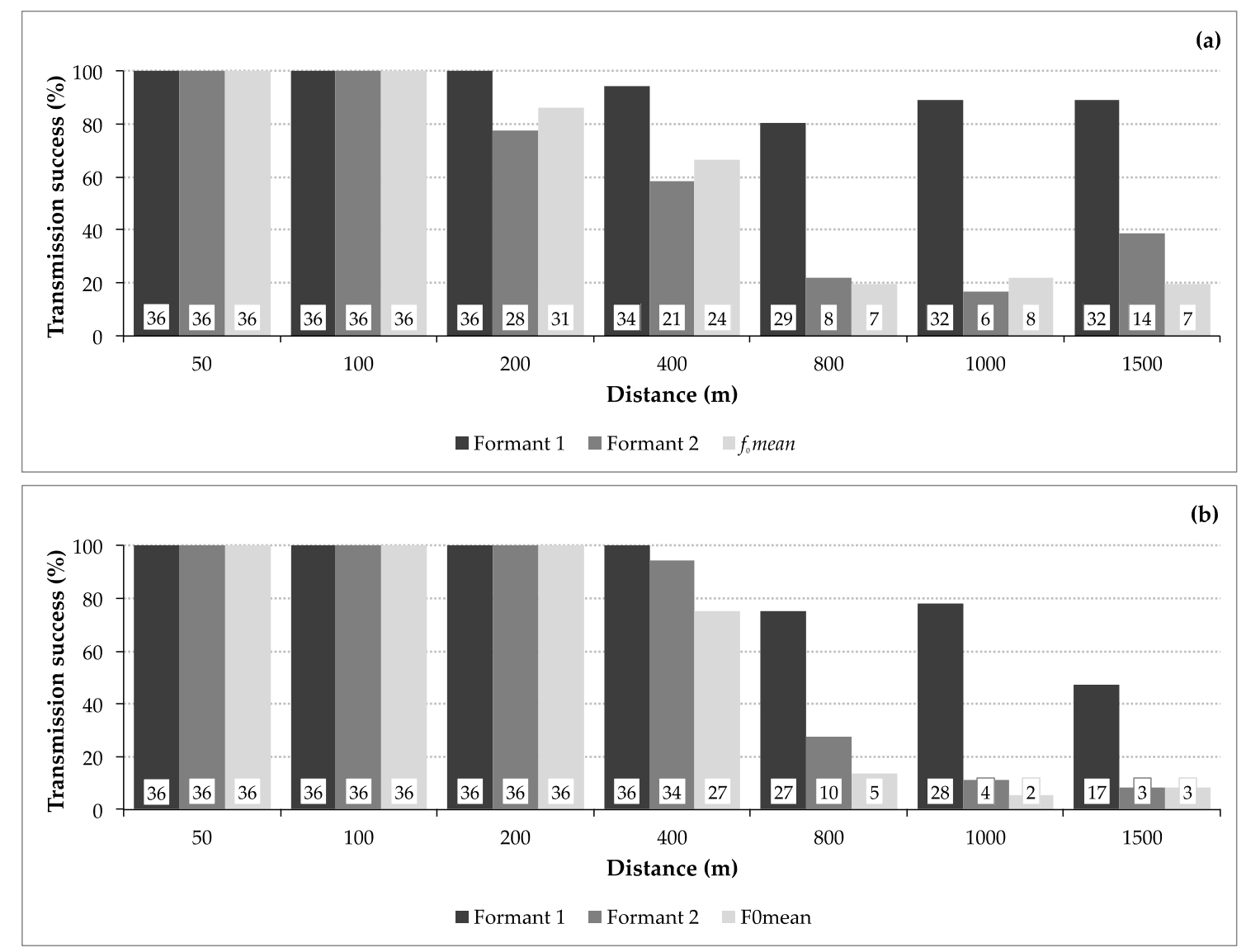

Figure 4. Transmission success (in percent) of $F 1, F 2$, and $f_{0}$ mean: Comparison of each acoustic feature between the (a) dense and (b) open habitat over 50 to $1500 \mathrm{~m}$ distance. Values given at the bottom of the bars indicate the absolute number of recordings successfully transmitted per distance. 
Our comparisons of frequency parameters measured at 100 to $1500 \mathrm{~m}$ distance to those analyzed at $50 \mathrm{~m}$ revealed no significant differences (except for F2 at $1000 \mathrm{~m}$ in the open habitat with $p=0.038$, note the difference of $\mathrm{N}=32$ though). In particular, the signal length (duration) of the re-recordings revealed deviations, showing significant differences between 800 m, $1000 \mathrm{~m}$, and $1500 \mathrm{~m}$, respectively (Table 2). Visual examples for successful propagations of $0 \%$ shifted and $25 \%$ downshifted playback stimuli between both habitats can be identified from Figure 5 .

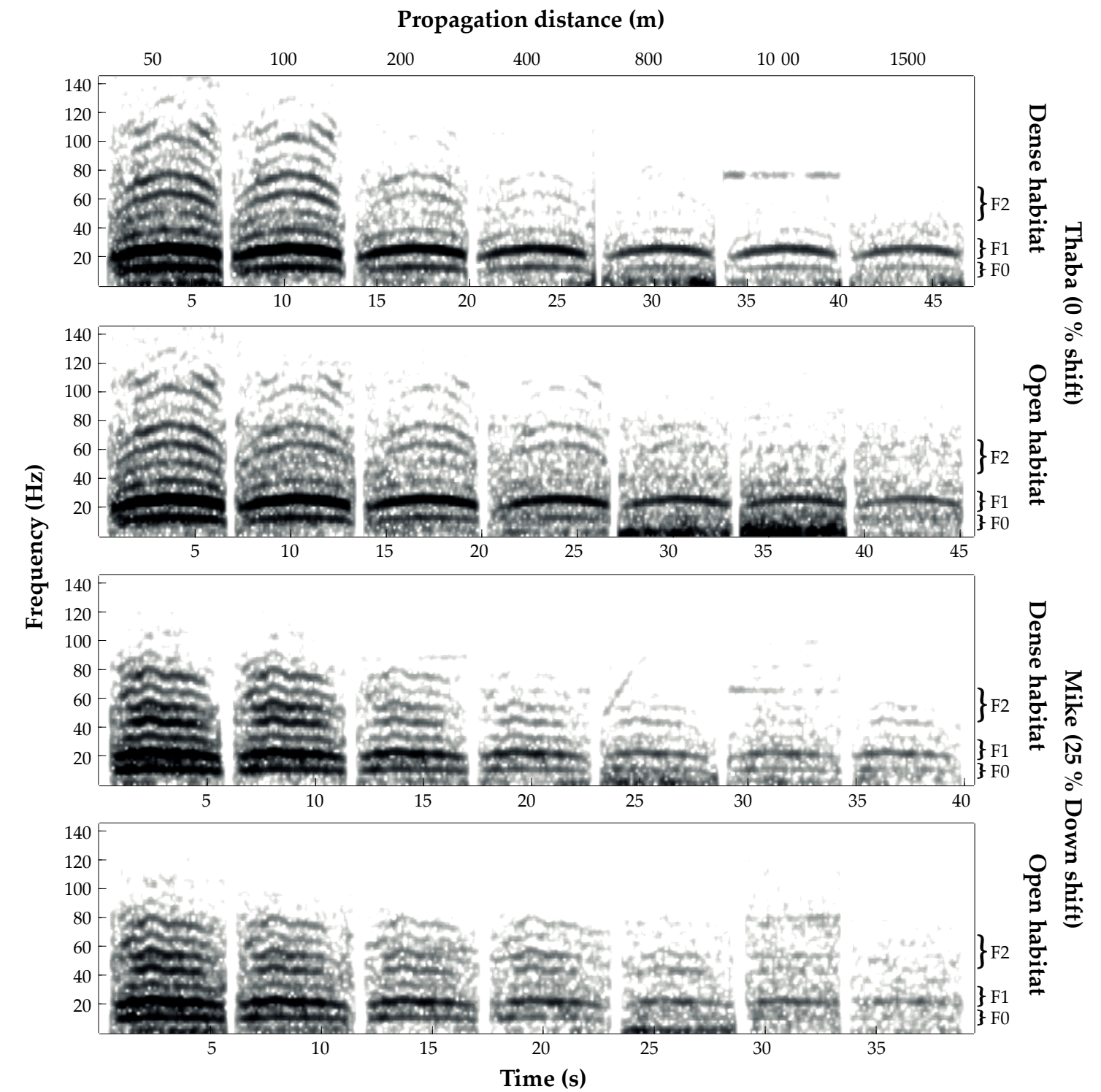

Figure 5. Spectrograms of concatenated $0 \%$ (from Thaba) and 25\% downshifted (from Mike) re-recordings conducted from 50 to $1500 \mathrm{~m}$ for both dense and open habitat, respectively. Curly brackets indicate location for $F 1$ showing the highest transmission consistency, while $f_{o}$ and $F 2$ were less well-defined (S_Tools-STx settings; analysis windows: Kaiser kessel, bandwidth: 2, overlap: 75\%). 
Table 2. Acoustic features recorded and measured at $50 \mathrm{~m}$ compared to all other distances ranging from 100-1500 m using Mann-Whitney U tests.

\begin{tabular}{|c|c|c|c|c|c|c|c|c|c|c|c|c|c|c|c|c|c|c|c|c|}
\hline \multirow{3}{*}{ Habitat } & \multirow{3}{*}{ Distance (m) } & \multicolumn{19}{|c|}{ Acoustic Features } \\
\hline & & \multicolumn{5}{|c|}{ Formant $1(\mathrm{~Hz})$} & \multicolumn{5}{|c|}{ Formant $2(\mathrm{~Hz})$} & \multicolumn{5}{|c|}{$f_{0}$ mean $(\mathrm{Hz})$} & \multicolumn{4}{|c|}{ Duration (s) } \\
\hline & & $\mathbf{N}$ & TS & $\mathrm{U}$ & $\mathrm{Z}$ & $\mathbf{P}$ & $\mathbf{N}$ & TS & $\mathbf{U}$ & $\mathrm{Z}$ & $\mathbf{P}$ & $\mathbf{N}$ & TS & $\mathbf{U}$ & $\mathrm{Z}$ & $\mathbf{P}$ & $\mathbf{N}$ & $\mathbf{U}$ & $\mathrm{Z}$ & $\mathbf{P}$ \\
\hline \multirow[t]{6}{*}{ Dense } & 50 & 36 & 100 & - & - & - & 36 & 100 & - & - & - & 36 & 100 & - & - & - & 36 & - & - & - \\
\hline & 50-100 & 36 & 100 & 636 & -0.135 & 0.892 & 36 & 100 & 646 & -0.028 & 0.978 & 36 & 100 & 645 & -0.039 & 0.969 & 36 & 622 & -0.298 & 0.765 \\
\hline & $50-200$ & 36 & 100 & 629 & -0.220 & 0.826 & 28 & 78 & 454 & -0.683 & 0.494 & 31 & 86 & 542 & -0.201 & 0.840 & 36 & 604 & -0.501 & 0.616 \\
\hline & $50-400$ & 34 & 94 & 587 & -0.300 & 0.764 & 21 & 58 & 356 & -0.364 & 0.716 & 24 & 67 & 364 & -1.027 & 0.305 & 36 & 557 & -1.031 & 0.303 \\
\hline & $50-800$ & 29 & 81 & 501 & -0.277 & 0.782 & 8 & 22 & 120 & -0.730 & 0.465 & 7 & 19 & 72 & -1.778 & 0.075 & 32 & 376 & -2.464 & 0.014 \\
\hline & $50-1000$ & 32 & 89 & 556 & -0.252 & 0.801 & 6 & 17 & 72 & -1.294 & 0.196 & 8 & 22 & 129 & -0.442 & 0.659 & 36 & 442 & -2.320 & 0.020 \\
\hline \multirow[t]{7}{*}{ Open } & 50 & 36 & 100 & - & - & - & 36 & 100 & - & - & - & 36 & 100 & - & - & - & 36 & - & - & - \\
\hline & 50-100 & 36 & 100 & 642 & -0.068 & 0.946 & 36 & 100 & 637 & -0.130 & 0.897 & 36 & 100 & 623 & -0.282 & 0.778 & 36 & 621 & -0.304 & 0.761 \\
\hline & $50-200$ & 36 & 100 & 608 & -0.451 & 0.652 & 36 & 100 & 646 & -0.023 & 0.982 & 36 & 100 & 645 & -0.039 & 0.969 & 36 & 644 & -0.051 & 0.960 \\
\hline & $50-400$ & 36 & 100 & 610 & -0.434 & 0.665 & 34 & 94 & 588 & -0.282 & 0.778 & 27 & 75 & 411 & -1.042 & 0.297 & 36 & 613 & -0.400 & 0.689 \\
\hline & $50-800$ & 27 & 75 & 450 & -0.500 & 0.617 & 10 & 28 & 118 & -1.665 & 0.096 & 5 & 14 & 62 & -1.117 & 0.264 & 34 & 435 & -2.086 & 0.037 \\
\hline & $50-1000$ & 28 & 78 & 453 & -0.697 & 0.486 & 4 & 11 & 26 & -2.074 & 0.038 & 2 & 6 & 36 & 0.000 & 1.000 & 31 & 350 & -2.616 & 0.009 \\
\hline & $50-1500$ & 17 & 47 & 298 & -0.162 & 0.871 & 3 & 8 & 30 & -1.265 & 0.206 & 3 & 8. & 45 & -0.475 & 0.635 & 21 & 138 & -3.979 & 0.000 \\
\hline
\end{tabular}

$\mathrm{N}=$ number of analyzed rumbles at 50-1500 m; TS = Transmission success of Formant 1, Formant 2 and $f_{0}$ mean in percent (\%); $\mathrm{U}=\mathrm{Mann}-\mathrm{Whitney} \mathrm{U}$ test $\mathrm{U}$-score; $\mathrm{Z}=\mathrm{Mann}-\mathrm{Whitney} \mathrm{U}$ test Z-score, $p=$ significance level $(p=0.05)$. 


\subsection{Transmission of Size Information}

VT length in savanna elephants is a reliable cue to body size [37,38]. By categorizing the recorded signals into two different size groups based on VT length estimations ranged from 2 to $5.47 \mathrm{~m}$, our data showed significant differences for F1 between rumbles simulating large (maturity group 1, MG 1) and small (maturity group 2, MG 2) male elephants. Dense habitat: $F 1_{\mathrm{MG}}=23.55 \pm 3.19 \mathrm{~Hz}(\mathrm{~N}=140)$, $F 1_{\mathrm{MG} 2}=35.28 \pm 4.47 \mathrm{~Hz}(\mathrm{~N}=95), X^{2}=169.073, \mathrm{df}=1, p<0.001 ;$ Open habitat: $F 1_{\mathrm{MG} 1}=23.67 \pm 3.29 \mathrm{~Hz}$ $\left.(\mathrm{N}=125), F 1_{\mathrm{MG} 2}=35.40 \pm 4.68 \mathrm{~Hz}(\mathrm{~N}=91), X^{2}=157.263, \mathrm{df}=1, p<0.001\right)$.

Moreover, Kruskal-Wallis tests confirmed stable transmission of $F 1$, with no significant differences of $F 1$ over distance for MG 1 at the dense $\left(\mathrm{N}=140, X^{2}=2.569, \mathrm{df}=6, p=0.861, \mathrm{r}=0.2\right)$ and open habitat $\left(\mathrm{N}=125, X^{2}=4.855, \mathrm{df}=6, p=0.563, \mathrm{r}=0.4\right)$. MG 2 was not statistically different in the dense habitat $\left(\mathrm{N}=95, X^{2}=7.055, \mathrm{df}=6, p=0.316, \mathrm{r}=0.7\right)$, while there was a significant change in the transmission of $F 1$ for MG 2 in the open habitat $\left(\mathrm{N}=91, X^{2}=20.681, \mathrm{df}=6, p=0.002, \mathrm{r}=2.167\right)$ over distance. However, performing pairwise comparisons using Dunn-Bonferroni post hoc corrections (adjusted significance level $p=0.002)$ did still not result in any significant differences for MG 2 in the open habitat $(p>0.002)$.

\subsection{Amplitude Attenuation}

Figure 6 shows that, overall, each acoustic parameter exhibited stronger attenuation with increasing distance for both habitats, with high effect sizes ( $f>0.5$ ) for all regression models. For instance, the SNR for F1 at $1500 \mathrm{~m}$ was $10.4 \pm 6.0 \mathrm{~dB}$ for the densely vegetated and $8.4 \pm 2.2 \mathrm{~dB}$ for the open habitat. Mean SNR \pm standard deviation for each recording distance (for $F 1, F 2$, and $f_{o}$ ) and per habitat are listed in Table S3. Additional ANOVAs (temperature, wind speed, humidity, and height were not included as covariates due to inhomogeneity of regression coefficients; measurements are given in Table S4) testing for differences between both habitats revealed significant differences for $F 1$ only $\left(\mathrm{N}_{\text {Dense }}=235,19.1 \pm 10.3 \mathrm{~dB}, \mathrm{~N}_{\text {Open }}=216,17.3 \pm 8.0 \mathrm{~dB}\right.$; Anova: $\left.\mathrm{F}=4.339, \mathrm{df}=1, p=0.038\right)$. In contrast, $F 2\left(\mathrm{~N}_{\text {Dense }}=149,18.6 \pm 12.2 \mathrm{~dB}, \mathrm{~N}_{\text {Open }}=159,19.5 \pm 7.6 \mathrm{~dB} ;\right.$ Anova: $\mathrm{F}=0.576, \mathrm{df}=1$, $p=0.448)$ and $f_{o}$ mean $\left(\mathrm{N}_{\text {Dense }}=148,20.2 \pm 7.8 \mathrm{~dB}, \mathrm{~N}_{\text {Open }}=136,19.9 \pm 6.0 \mathrm{~dB} ;\right.$ Anova: $\mathrm{F}=2.080, \mathrm{df}=1$, $p=0.150)$ showed no differences.

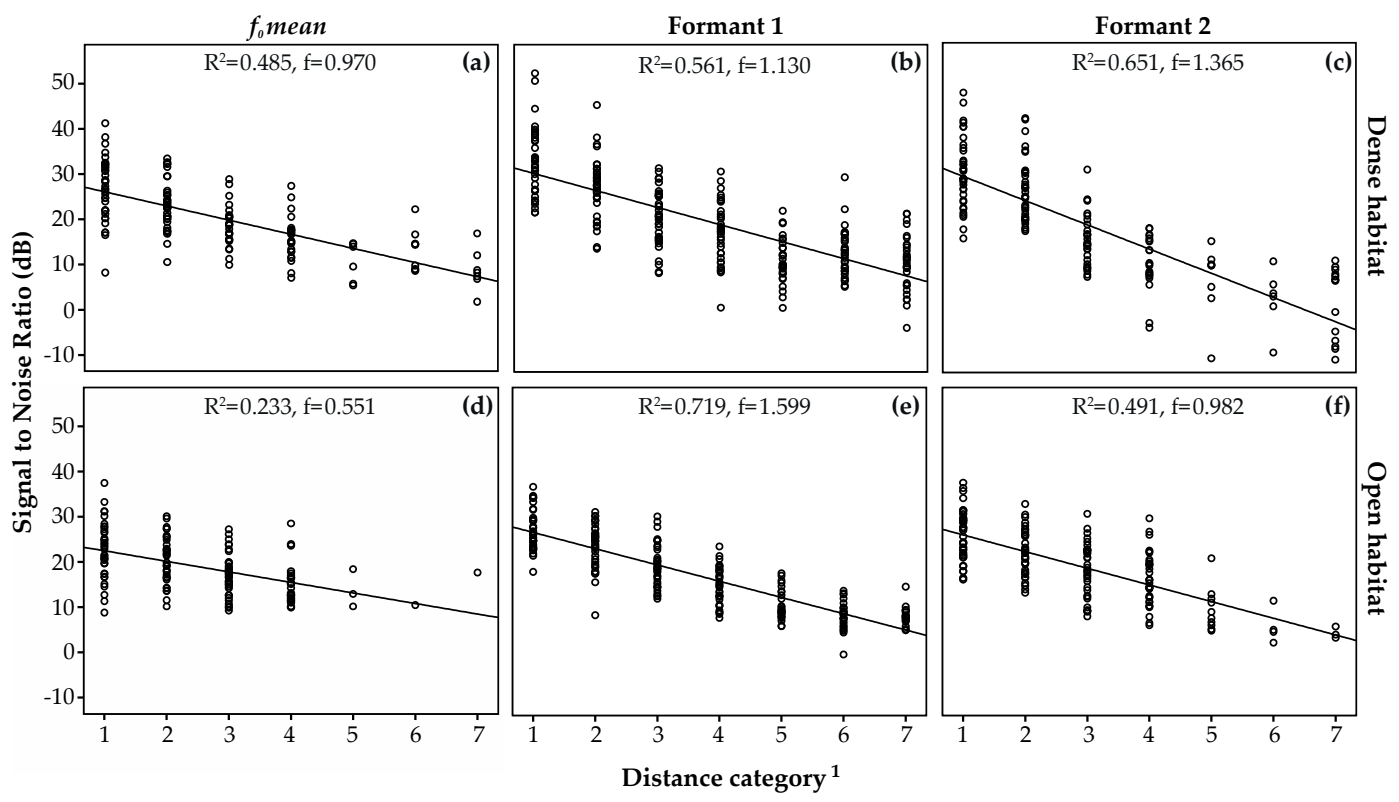

Figure 6. Signal-to-Noise ratio and regression lines for $f_{o}$ mean (a,d), Formant 1 (b,e), and Formant 2 $(\mathbf{c}, \mathbf{f})$ per habitat over all recording distances (top three figures represent the densely vegetated and the three bottom figures the open habitat) show formant and $f_{o}$ attenuation with increasing distances. Cohen's $\mathrm{f}$ indicates the effect sizes ( $\mathrm{f}>0.5$ represents a strong effect size). ${ }^{1}$ Distance category: $1=50 \mathrm{~m}$, $2=100 \mathrm{~m}, 3=200 \mathrm{~m}, 4=400 \mathrm{~m}, 5=800 \mathrm{~m}, 6=1000 \mathrm{~m}, 7=1500 \mathrm{~m}$. 


\section{Discussion}

The field propagation experiments described in this paper reveal novel insights into the transmission of the infrasonic and long-ranging savanna elephant rumble. Our results show that the stability of spectral features in rumbles of four male savanna elephants, conveying measurable size-related information [37], prevailed over distances of up to $1.5 \mathrm{~km}$ under two different habitats. However, it remains to be investigated whether savanna elephants can indeed perceive rumbles with the obtained SNR values. Sounds are processed within listener's auditory system, but in savanna elephants, to our knowledge there is no data available on their hearing threshold or other hearing capabilities, such as directional hearing, sound localization, antimasking mechanisms, critical bandwidths, and critical ratios [64]. In addition, hearing sensitivity might as well be influenced by sex and age [65-69] in this species.

Previous research using playback experiments demonstrated that savanna elephant rumbles encode acoustic information about sex, reproductive state, and even social identity [38,70-73]. Savanna elephants are capable of not only recognizing rumbles of other family and bond group members within their population but also of discriminating calls from conspecifics they encountered more or less frequently [71]. It has also been shown that savanna elephants detect contact rumbles broadcasted at distances ranging between 0.5 and $2.5 \mathrm{~km}$, revealing their ability to recognize rumbles and to assign them to family members at distances up to $1.5 \mathrm{~km}[33,54]$. Nonetheless, as vocalizations propagate through an animal's natural environment, they degrade over distance in various acoustic parameters such as amplitude (source intensity) and frequency patterns. This can potentially affect the detection of acoustic features and eventually hinder savanna elephants' discriminative abilities. McComb et al. [54] found that $F 2$ (harmonics region around $115 \mathrm{~Hz}$ ) was the most prominent and persistent acoustic feature measured in rumbles over distance. They suggested accordingly that frequencies above the infrasonic range play an important role for social recognition in savanna elephants. Our findings provide a key difference to these previous results, as our transmission profiles showed that efficiency and persistency were highest for $F 1$ and a clear loss of higher harmonics in the F2 region, as shown in forest elephants [74]. Yet, importantly, our results support McComb et al.'s conclusion highlighting the relevant role of frequencies above infrasound in savanna elephant communication (given that $F 1$ is usually around 25 to $35 \mathrm{~Hz}$ ). We observed a similar degradation pattern between $F 2$ and $f_{o}$, where contour detection in both experimental habitats was most consistent between 50 and $400 \mathrm{~m}$, but dropped increasingly from $800 \mathrm{~m}$ to $1.5 \mathrm{~km}$.

In contexts of male competition, formant frequencies have been described in several mammal species (e.g., red deer [42] and koala [75]) as robust acoustic indicators of a caller's body size (more so than $f_{o}$ [45]). In a previous research project we revealed that formant frequencies generated via the nasal vocal tract serve as an honest cue to the maturity status (age and body size) in male savanna elephants [37]. We show that this information is likely to be transmitted over distance since significant differences between both bull size categories $(\leq 3 \mathrm{~m}$ and $>3 \mathrm{~m}$ ) remained in both habitats (yet, our sample size is considerably small). Note, however, that VT length estimations, and hence body size predictions in the present study, were based on individual $F 1$ frequencies instead of formant spacing because $F 2$ transmission was inconsistent and difficult to identify, particularly at larger distances. Earlier studies raised concerns about the reliability of using one formant as a single cue for VT length, due to environmental factors potentially degrading the chosen frequency band and to sensitivity to possible deviations from the uniform tube assumption $[45,76]$. Therefore, this might lead to imprecise VT length estimations. Formant dispersion, in contrast, relies on redundant formant spacing patterns and is considered to be more resistant to adverse environmental distortion factors and individual formant variability [45]. Consequently, most playback studies examining the relevance of formants used formant dispersion as a measure of size discrimination $[43,44,77,78]$. Other perceptual studies, however, showed that some non-human primates place more weight on the position of $F 1$ than $F 2$ [79]. Since $F 2$ was measured inconsistently at longer recording distances, we estimated VT length using $F 1$ locations. Furthermore, we provide evidence that, particularly, F1 frequencies propagated with 
higher consistency than $f_{o}$ and $F 2$ across and between all measuring points in both tested habitats. Our results demonstrate that $F 1$ in nasally emitted social rumbles may travel up to $1.5 \mathrm{~km}$ and underline their informative value and potential relevance for long-distance communication where body-size assessment matters.

The spectral and temporal acoustic characteristics of a sound determine how far it will travel through the environment $[9,11]$. However, sound propagation and sound detectability are also critically determined by the habitat structure, ambient noise source, and local atmospheric conditions (such as temperature, wind, and humidity). These can either favor or impede sound propagation [7]. The speed of sound in any given terrestrial environment depends on air temperature. For instance, the approximate speed of airborne sound at $20^{\circ} \mathrm{C}$ is $343.5 \mathrm{~m} / \mathrm{s}$ (using the formula $\mathrm{c}=331.4+0.607 \times$ ambient temperature $\left.\left({ }^{\circ} \mathrm{C}\right)[61]\right)$. Rising temperatures boost sound velocity. Humidity may also increase the speed of sound, e.g., at $100 \%$ relative humidity and $20{ }^{\circ} \mathrm{C}$, sound velocity is approximately $0.3 \%$ greater than at $30 \%$ relative humidity $[12,61]$. Furthermore, empirical data and computer modeling of the African savannah revealed that optimal conditions for elephant low-frequency sound propagation are given under low wind and cool temperatures, particularly $1-2 \mathrm{~h}$ after sunset when air at ground level cools down rapidly [80]. Therefore, Garstang et al. [80] proposed that savanna elephants adapt their long-ranging and low-frequency calling rates to atmospheric conditions. These authors suggested that, by making use of near-surface temperature inversions, savanna elephants can increase their call propagation ranges considerably (up to $10 \mathrm{~km}$ under ideal atmospheric conditions) [80]. However, whether they actually do adjust their vocalizations to optimal atmospheric conditions is not supported by any data provided so far.

To date, the behavioral responses of wild savanna elephants to playback stimuli have been experimentally documented at a maximum distance of $2.5 \mathrm{~km}$ only [54] (but were estimated to be audible to conspecifics at least $4 \mathrm{~km}$ away from the source using data extrapolations [33]). Furthermore, wind can be directly related to turbulence and cause more than mere attenuation along a sound's broadcast direction [7]. Our experiments were thus always conducted under low wind conditions. Nonetheless, although wind speed measurements were conducted at the site of the re-recordings, we cannot rule out that sudden wind gusts between both vehicles might have affected the broadcasted signals.

Differences in vegetation, topography, and atmospheric conditions can influence sound transmission via reverberation, amplitude fluctuations, and attenuation at all frequencies, and result in temporal and spectral degradation of various degree [7-12]. While we did not find any frequency-dependent differences in propagation between open and dense habitats, we did observe deviations in call duration at larger recording distances. However, to what extent temporal degradation processes might play a role for signal detection or distance assessment requires further investigation.

Signal detection and recognition strongly depend on the signal-to-noise ratio (SNR), a measure of a signal's maximum amplitude relative to ambient noise. Therefore, ambient noise level (in addition to atmospheric distortion factors) also plays an important role in sound detection [9]. However, it is suggested that signal amplitude alone is not entirely reliable cue for distance assessment and that temporal and/or frequency-specific structures are likely to serve as more complex acoustic cues [17-19]. Our analyses of rumble broadcast data confirmed the prediction for degradation trends for $F 1, F 2$, and $f_{o}$ mean: transmission efficiency and intensity of rumbles decrease progressively with increasing distance. Not only unnoticed wind gusts between both vehicles during the experiments but height differences might also have played a role in sound transmission through changes in SNRs. The terrain of the open habitat showed greater height differences between the subwoofer and the respective recording distance than the more densely vegetated habitat. However, if this effect on SNR was present it appears negligible as, overall, we found no noticeable differences in transmission efficiency between both habitats. However, low-frequency sound waves tend to be enhanced particularly when traveling above porous surfaces (such as soil or sand) because larger sound wavelengths penetrate the ground pores less [16]. Although this insight was not obtained experimentally, we cautiously assume 
that constructive ground effects in the tested habitat could likely enforce long-distance rumbles by superimposed reflections, as it has been recently suggested for the densely vegetated habitat of forest elephants [74].

The pioneering field playback studies in the early 1990s and 2000s conducted by Langbauer et al. [33] and McComb et al. [54] provided first evidence on the nature of rumbles and their importance for long-distance communication. Our results are in general in agreement with savanna elephant's large body size allowing the production of low-frequency and high-intensity rumbles, both favoring propagation to distances over which this species communicates. McComb et al. [54] found that frequency peaks in rumbles re-recorded over several hundred meters remained most prominent and stable in the F2 region. Our results indicate that formants likely serve as long-range signal in savanna elephants, instead of being merely relevant for short- to medium-range communication, as previously suggested [54]. Importantly (both from a theoretical and practical standpoint), most of the acoustic energy in our study was concentrated and persisted at the $F 1$ frequency position, compared to $F 2$ and $f_{o}$ mean. The use of female rumbles by McComb et al. [54] and male rumbles in our study is a potential factor explaining deviations between both studies, i.e., sexual vocal dimorphism in social rumbles [38], which however requires further testing. Finally, differences between our findings might merely reflect the use of different equipment (e.g., speaker, variation of frequency responses between microphones and analog DAT recorders [54]).

\section{Conclusions}

In conclusion, our study describes how the environment can influence propagation of rumbles and what kind of information might be transmitted successfully over distance. Future field playback experiments using formant-shifts, and thus different size variants of male rumbles, could provide information on two aspects: assessing the size discrimination abilities of savanna elephant bulls based solely on vocalizations, and identifying how rumble degradation over distance relates to its perception in this species.

Supplementary Materials: The following are available online at http:/ /www.mdpi.com/2076-2615/8/10/167/s1; Table S1: Formant-related features measured in S_Tools-STx; Table S2: GPS coordinates and topographic height per habitat and recording distance; Table S3: Signal-to-noise ratios: mean, \pm standard deviation (Stdev); Table S4: Atmospheric conditions (mean \pm standard deviation) for each recording distance and habitat.

Author Contributions: Conceptualization, A.B.; Methodology, A.B., M.G., M.B., and A.S.; Software, A.B., M.B.; Validation, A.S.; Formal Analysis, A.B.; Investigation, A.B., M.B., and A.S.; Resources, A.S.; Data Curation, A.B.; Writing-Original Draft Preparation, A.B.; Writing-Review \& Editing, A.B., A.S., and M.G.; Visualization, A.B.; Supervision, A.S.; Project Administration, A.B. and A.S.; Funding Acquisition, A.S.

Funding: This research was funded by the FWF, the Austrian Science Fund (P26448). During editing M.G. was supported by funding from a Fyssen Foundation post-doctoral study grant.

Acknowledgments: We are grateful to SanParks and Sam Ferreira, the Addo Elephant National Park management, and most importantly John Adendorff, Angela Gaylard, Roxanne Erusan, the rangers, and the entire team of the Gorah Elephant Camp for enabling and strongly supporting our research. We also thank all participating institutions: Sean Hensman (Adventures with Elephants), Brett Mitchel (Pilanesberg Back Safaris), Andre Kotze (Elephant Whisperers), and Debbie Young (African Elephant Research Unit, Knysna Elephant Park, and Addo Elephant Back Safaris) for enabling acoustic recordings at their institutions. We are further grateful to AVIS van rental Port Elizabeth and Pickfords Port Elizabeth for generously supporting our field research with an impressive fee reduction. We thank the Acoustic research institute of the Austrian academy of science, particularly Ing. Anton Noll and Jonathan Stuefer, B.A., for their technical input and scientific advice. We also thank Michael Stachowitsch for editing the text. We are grateful to Tecumseh Fitch and Thomas Bugnyar for strongly supporting our research at the Department of Cognitive Biology.

Conflicts of Interest: The authors declare no conflicts of interest. The funders had no role in the design of the study, in the collection, analyses, or interpretation of data; in the writing of the manuscript, or in the decision to publish the results. 


\section{References}

1. Aureli, F.; Schaffner, C.M.; Boesch, C.; Bearder, S.K.; Call, J.; Chapman, C.A.; Connor, R.; Fiore, A.D.; Dunbar, R.I.M.; Henzi, S.P.; et al. Fission-Fusion Dynamics: New Research Frameworks. Curr. Anthropol. 2008, 49, 627-654. [CrossRef]

2. Sueur, C.; King, A.J.; Conradt, L.; Kerth, G.; Lusseau, D.; Mettke-Hofmann, C.; Schaffner, C.M.; Williams, L.; Zinner, D.; Aureli, F. Collective decision-making and fission-fusion dynamics: A conceptual framework. Oikos 2011, 120, 1608-1617. [CrossRef]

3. McComb, K.; Reby, D. Vocal communication networks in large terrestrial mammals. In Animal Communication Networks; McGregor, P.K., Ed.; Cambridge University Press: Cambridge, UK, 2005; pp. 372-389.

4. Taylor, A.M.; Reby, D. The contribution of source-filter theory to mammal vocal communication research. J. Zool. 2010, 280, 221-236. [CrossRef]

5. Ryan, M.J.; Kime, N.M. Selection on Long-Distance Acoustic Signals. In Acoustic Communication; Simmons, A.M., Fay, R.R., Popper, A.N., Eds.; Springer: New York, NY, USA, 2003; pp. 225-274.

6. Naguib, M.; Wiley, R.H. Estimating the distance to a source of sound: Mechanisms and adaptations for long-range communication. Anim. Behav. 2001, 62, 825-837. [CrossRef]

7. Wiley, R.H.; Richards, D.G. Physical Constraints on Acoustic Communication in the Atmosphere: Implications for the Evolution of Animal Vocalizations. Behav. Ecol. Sociobiol. 1978, 3, 69-94. [CrossRef]

8. Marten, K.; Marler, P. Sound Transmission and Its Significance for Animal Vocalization: I. Temperate Habitats. Behav. Ecol. Sociobiol. 1977, 2, 271-290. [CrossRef]

9. Forrest, T.G. From sender to receiver: Propagation and environmental effects on acoustic signals. Am. Zool. 1994, 34, 644-654. [CrossRef]

10. Piercy, J.E.; Embleton, T.F.W. Review of noise propagation in the atmosphere. J. Acoust. Soc. Am. 1977, 61, 1403-1418. [CrossRef] [PubMed]

11. Wiley, R.D.; Richards, D.C. Adaptation for acoustic communication in birds: Sound transmission and signal detection. In Acoustic Communication in Birds; Kroodsma, D.E., Miller, E.H., Quellet, H., Eds.; Academic Press: Cambridge, UK, 1982; pp. 131-181.

12. Marten, K.; Quine, D.; Marler, P. Sound Transmission and Its Significance for Animal Vocalization: II. Tropical Forest Habitats. Behav. Ecol. Sociobiol. 1977, 2, 291-302. [CrossRef]

13. Ey, E.; Rahn, C.; Hammerschmidt, K.; Fischer, J. Wild Female Olive Baboons Adapt their Grunt Vocalizations to Environmental Conditions. Ethology 2009, 115, 493-503. [CrossRef]

14. Slabbekoorn, H.; Ellers, J.; Smith, T.B. Birdsong and Sound Transmission: The Benefits of Reverberations. Condor 2002, 104, 564-573. [CrossRef]

15. Nemeth, E.; Dabelsteen, T.; Pedersen, S.B.; Winkler, H. Rainforests as concert halls for birds: Are reverberations improving sound transmission of long song elements? J. Acoust. Soc. Am. 2006, 119, 620-626. [CrossRef] [PubMed]

16. Attenborough, K. Sound propagation close to the ground. Annu. Rev. Fluid Mech. 2002, 34, 51-82. [CrossRef]

17. Brumm, H.; Naguib, M. Chapter 1 Environmental Acoustics and the Evolution of Bird Song. In Advances in the Study of Behavior; Academic Press: Cambridge, UK, 2009; Volume 40, pp. 1-33.

18. Richards, D.G. Estimation of Distance of Singing Conspecifics by the Carolina Wren. Auk 1981, 98, 127-133.

19. Morton, E.S. Grading, Discreteness, Redundancy, and Motivation-Structural Rules. In Acoustic Communication in Birds; Kroodsma, D.E., Miller, E.H., Eds.; Academic Press: San Diego, CA, USA, 1982; pp. 183-212.

20. Ringler, M.; Szipl, G.; Hödl, W.; Khil, L.; Kofler, B.; Lonauer, M.; Provin, C.; Ringler, E. Acoustic ranging in poison frogs-it is not about signal amplitude alone. Behav. Ecol. Sociobiol. 2017, 71, 114. [CrossRef] [PubMed]

21. Sanvito, S.; Galimberti, F. Source level of male vocalizations in the genus Mirounga: Repeatability and correlates. Bioacoustics 2003, 14, 47-59. [CrossRef]

22. Wyman, M.T.; Mooring, M.S.; McCowan, B.; Penedo, M.C.T.; Hart, L.A. Amplitude of bison bellows reflects male quality, physical condition and motivation. Anim. Behav. 2008, 76, 1625-1639. [CrossRef]

23. Waser, P.M.; Brown, C.H. Habitat acoustics and primate communication. Am. J. Primatol. 1986, 10, $135-154$. [CrossRef]

24. Morton, E.S. Ecological Sources of Selection on Avian Sounds. Am. Naturalist 1975, 109, 17-34. [CrossRef] 
25. Fischer, J.; Hammerschmidt, K.; Cheney, D.L.; Seyfarth, R.M. Acoustic features of male baboon loud calls: Influences of context, age, and individuality. J. Acoust. Soc. Am. 2002, 111, 1465-1474. [CrossRef] [PubMed]

26. Mitani, J.C.; Nishida, T. Contexts and social correlates of long-distance calling by male chimpanzees. Anim. Behav. 1993, 45, 735-746. [CrossRef]

27. Gersick, A.S.; Cheney, D.L.; Schneider, J.M.; Seyfarth, R.M.; Holekamp, K.E. Long-distance communication facilitates cooperation among wild spotted hyaenas, Crocuta crocuta. Anim. Behav. 2015, 103, 107-116. [CrossRef] [PubMed]

28. Poole, J.H.; Payne, K.; Langbauer, W.R.; Moss, C.J. The social contexts of some very low frequency calls of African elephants. Behav. Ecol. Sociobiol. 1988, 22, 385-392. [CrossRef]

29. Wittemyer, G.; Douglas-Hamilton, I.; Getz, W.M. The socioecology of elephants: Analysis of the processes creating multitiered social structures. Anim. Behav. 2005, 69, 1357-1371. [CrossRef]

30. Moss, C.J.; Poole, J.H. Relationships and social structure of African elephants. In Primate Social Relations: An Integrated Approach; Hinde, R.A., Ed.; Blackwell Scientific Publication: Oxford, UK, 1983; pp. 315-325.

31. O'Connell-Rodwell, C.E.; Wood, J.D.; Wyman, M.; Redfield, S.; Puria, S.; Hart, L.A. Antiphonal vocal bouts associated with departures in free-ranging African elephant family groups (Loxodonta africana). Bioacoustics 2012, 21, 215-224. [CrossRef]

32. Soltis, J. Vocal communication in African Elephants (Loxodonta africana). Zoo Biol. 2010, 29, $192-209$. [CrossRef] [PubMed]

33. Langbauer, W.R.; Payne, K.B.; Charif, R.A.; Rapaport, L.; Osborn, F. African Elephants Respond to Distant Playbacks of Low-Frequency Conspecific Calls. J. Exp. Biol. 1991, 157, 35-46.

34. Poole, J.H. Behavioral contexts of elephant acoustic communication. In The Amboseli Elephants: A Long-Term Perspective on A Long-Lived Mammal; Moss, C.J., Croze, H., Lee, P.C., Eds.; The University of Chicago: Chicago, IL, USA, 2011; pp. 125-161.

35. Stoeger, A.S.; Zeppelzauer, M.; Baotic, A. Age-group estimation in free-ranging African elephants based on acoustic cues of low-frequency rumbles. Bioacoustics 2014, 23, 1-16. [CrossRef] [PubMed]

36. Soltis, J.; Blowers, T.E.; Savage, A. Measuring positive and negative affect in the voiced sounds of African elephants (Loxodonta africana). J. Acoust. Soc. Am. 2011, 129, 1059-1066. [CrossRef] [PubMed]

37. Stoeger, A.S.; Baotic, A. Information content and acoustic structure of male African elephant social rumbles. Sci. Rep. 2016, 6, 27585. [CrossRef] [PubMed]

38. Baotic, A.; Stoeger, A.S. Sexual dimorphism in African elephant social rumbles. PLoS ONE 2017, 12 , e0177411. [CrossRef] [PubMed]

39. Leighty, K.A.; Soltis, J.; Wesolek, C.M.; Savage, A. Rumble vocalizations mediate interpartner distance in African elephants, Loxodonta africana. Anim. Behav. 2008, 76, 1601-1608. [CrossRef]

40. Titze, I.R. Principles of Voice Production; Prentice Hall: Englewood Cliffs, NJ, USA, 1994.

41. Titze, I.R. Vocal Fold Mass Is Not A Useful Quantity for Describing F0 in Vocalization. J. Speech Lang. Hear. Res. 2011, 54, 520-522. [CrossRef]

42. Reby, D.; McComb, K.; Cargnelutti, B.; Darwin, C.; Fitch, W.T.; Clutton-Brock, T. Red deer stags use formants as assessment cues during intrasexual agonistic interactions. Philos. Trans. R. Soc. Lond. B Biol. Sci. 2005, 272, 941-947. [CrossRef] [PubMed]

43. Charlton, B.; Ellis, W.H.; Larkin, R.; Tecumseh Fitch, W. Perception of size-related formant information in male koalas (Phascolarctos cinereus). Anim. Cogn. 2012, 15, 999-1006. [CrossRef] [PubMed]

44. Taylor, A.M.; Reby, D.; McComb, K. Size communication in domestic dog, Canis familiaris, growls. Anim. Behav. 2010, 79, 205-210. [CrossRef]

45. Fitch, W.T. Vocal tract length and formant frequency dispersion correlate with body size in rhesus macaques. J. Acoust. Soc. Am. 1997, 102, 1213-1222. [CrossRef] [PubMed]

46. Fitch, W.; Hauser, M. Unpacking "Honesty": Vertebrate Vocal Production and the Evolution of Acoustic Signals. In Acoustic Communication; Simmons, A., Fay, R., Popper, A., Eds.; Springer: New York, NY, USA, 2003; Volume 16, pp. 65-137.

47. Charlton, B.D.; Reby, D. The evolution of acoustic size exaggeration in terrestrial mammals. Nat. Commun. 2016, 7, 12739. [CrossRef] [PubMed]

48. Herbst, C.T.; Švec, J.G.; Lohscheller, J.; Frey, R.; Gumpenberger, M.; Stoeger, A.S.; Fitch, W.T. Complex vibratory patterns in an elephant larynx. J. Exp. Biol. 2013, 216, 4054-4064. [CrossRef] [PubMed] 
49. Stoeger, A.S.; Heilmann, G.; Zeppelzauer, M.; Ganswindt, A.; Hensman, S.; Charlton, B.D. Visualizing Sound Emission of Elephant Vocalizations: Evidence for Two Rumble Production Types. PLoS ONE 2012, 7, e48907. [CrossRef] [PubMed]

50. Low, A.B.; Rebelo, A.G. Vegetation of South Africa, Lesotho and Swaziland: A Companion to the Vegetation Map of South Africa, Lesotho and Swaziland; Department of Environmental Affairs and Tourism: Pretoria, South Africa, 1998.

51. Whitehouse, A.M.; Irwin, P.R. A field Guide to the Addo Elephants; Rhodes University, Environmental Education Unit: Port Elizabeth, South Africa, 2002.

52. Whitehouse, A.M.; Schoeman, D.S. Ranging behaviour of elephants within a small, fenced area in Addo Elephant National Park, South Africa. Afr. Zool. 2003, 38, 95-108. [CrossRef]

53. Garstang, M. Long-distance, low-frequency elephant communication. J. Comp. Physiol. A 2004, 190, 791-805. [CrossRef] [PubMed]

54. McComb, K.; Reby, D.; Baker, L.; Moss, C.; Sayialel, S. Long-distance communication of acoustic cues to social identity in African elephants. Anim. Behav. 2003, 65, 317-329. [CrossRef]

55. Soltis, J.; Leighty, K.A.; Wesolek, C.M.; Savage, A. The Expression of Affect in African Elephant (Loxodonta africana) Rumble Vocalizations. J. Comp. Psychol. 2009, 123, 222-225. [CrossRef] [PubMed]

56. Soltis, J.; King, L.E.; Douglas-Hamilton, I.; Vollrath, F.; Savage, A. African Elephant Alarm Calls Distinguish between Threats from Humans and Bees. PLoS ONE 2014, 9, e89403. [CrossRef] [PubMed]

57. Boersma, P.; Weenink, D. Praat: Doing Phonetics by Computer [Computer Program]. Version 6.0.15. 2014. Available online: http:/ / www.praat.org/ (accessed on 25 March 2016).

58. AppicDesign. GPS Tour [Mobile Application Software]. Version 2.0. 2016. Available online: http:/ /itunes. apple.com (accessed on 24 March 2016).

59. UNAVCO. Geoid Height Calculator. 2018. Available online: https://www.unavco.org/software/geodeticutilities / geoid-height-calculator/geoid-height-calculator.html (accessed on 26 March 2016).

60. Noll, A.; White, J. S_Tools-STx Online Manual. Available online: https://www.kfs.oeaw.ac.at/stx/docs / wiki/index.php (accessed on 21 March 2017).

61. Michelsen, A. Sound Reception in Different Environments. In Sensory Ecology: Review and Perspectives; Ali, M.A., Ed.; Springer: Boston, MA, USA, 1978; pp. 345-373.

62. Cohen, J. Multiple Regression and Correlation Analysis. In Statistical Power Analysis for the Behavioral Sciences, 2nd ed.; Lawrence Erlbaum Associates: New York, NY, USA; Routledge: Abingdon, UK, 1988; pp. 407-466.

63. SPSS-Inc. IBM SPSS Statistics v.23; SPSS Inc.: Chicago, IL, USA, 2015.

64. Brumm, H.; Slabbekoorn, H. Acoustic Communication in Noise. In Advances in the Study of Behavior; Academic Press: Cambridge, UK, 2005; Volume 35, pp. 151-209.

65. Schopf, C.; Zimmermann, E.; Tünsmeyer, J.; Kästner, S.B.R.; Hubka, P.; Kral, A. Hearing and Age-Related Changes in the Gray Mouse Lemur. J. Assoc. Res. Otolaryngol. 2014, 15, 993-1005. [CrossRef] [PubMed]

66. Boettcher, F.A.; Mills, J.H.; Norton, B.L. Age-related changes in auditory evoked potentials of gerbils. I. Response amplitudes. Hear. Res. 1993, 71, 137-145. [CrossRef]

67. Boettcher, F.A.; Mills, J.H.; Norton, B.L.; Schmiedt, R.A. Age-related changes in auditory evoked potentials of gerbils. II. Response latencies. Hear. Res. 1993, 71, 146-156. [CrossRef]

68. Boettcher, F.A.; White, D.R.; Mills, J.H.; Schmiedt, B.N. Age-related changes in auditory evoked potentials of gerbils. III. Low-frequency responses and repetition rate effects. Hear. Res. 1995, 87, 208-219. [CrossRef]

69. Torre, P.; Fowler, C.G. Age-related changes in auditory function of rhesus monkeys (Macaca mulatta). Hear. Res. 2000, 142, 131-140. [CrossRef]

70. Poole, J.H. Signals and assessment in African elephants: Evidence from playback experiments. Anim. Behav. 1999, 58, 185-193. [CrossRef] [PubMed]

71. McComb, K.; Moss, C.; Sayialel, S.; Baker, L. Unusually extensive networks of vocal recognition in African elephants. Anim. Behav. 2000, 59, 1103-1109. [CrossRef] [PubMed]

72. Stoeger, A.S.; Baotic, A. Male African elephants discriminate and prefer vocalizations of unfamiliar females. Sci. Rep. 2017, 7, 46414. [CrossRef] [PubMed]

73. Soltis, J.; Leong, K.; Savage, A. African elephant vocal communication II: Rumble variation reflects the individual identity and emotional state of callers. Anim. Behav. 2005, 70, 589-599. [CrossRef] 
74. Hedwig, D.; DeBellis, M.; Wrege, P.H. Not so far: Attenuation of low-frequency vocalizations in a rainforest environment suggests limited acoustic mediation of social interaction in African forest elephants. Behav. Ecol. Sociobiol. 2018, 72, 33. [CrossRef]

75. Charlton, B.D.; Whisson, D.A.; Reby, D. Free-Ranging Male Koalas Use Size-Related Variation in Formant Frequencies to Assess Rival Males. PLoS ONE 2013, 8, e70279. [CrossRef] [PubMed]

76. Riede, T.; Fitch, T. Vocal tract length and acoustics of vocalization in the domestic dog (Canis familiaris). J. Exp. Biol. 1999, 202, 2859-2867. [PubMed]

77. Charlton, B.D.; Zhihe, Z.; Snyder, R.J. Giant pandas perceive and attend to formant frequency variation in male bleats. Anim. Behav. 2010, 79, 1221-1227. [CrossRef]

78. Reby, D.; McComb, K. Anatomical constraints generate honesty: Acoustic cues to age and weight in the roars of red deer stags. Anim. Behav. 2003, 65, 519-530. [CrossRef]

79. Sinnott, J.M.; Brown, C.H.; Malik, W.T.; Kressley, R.A. A multidimensional scaling analysis of vowel discrimination in humans and monkeys. Percept. Psychophys. 1997, 59, 1214-1224. [CrossRef] [PubMed]

80. Garstang, M.; Larom, D.; Raspet, R.; Lindeque, M. Atmospheric controls on elephant communication. J. Exp. Biol. 1995, 198, 939-951. [PubMed]

(C) 2018 by the authors. Licensee MDPI, Basel, Switzerland. This article is an open access article distributed under the terms and conditions of the Creative Commons Attribution (CC BY) license (http:/ / creativecommons.org/licenses/by/4.0/). 